\title{
INTEGRATION OF KNOWLEDGE THROUGH ONLINE CLASSES IN THE LEARNING ENHANCEMENT OF STUDENTS
}

\author{
Leovigildo Lito D. Mallillin ${ }^{1 i}$, \\ Eduardo A. Carag', \\ Jocelyn B. Mallillin'3, \\ Regilito D. Laurel ${ }^{4}$ \\ ${ }^{1}$ Lecturer, PhD, Gulf College, \\ Sultanate of Oman \\ ${ }^{2}$ Associate Professor V, PhD, \\ Cagayan State University, \\ Tuguegarao City, Philippines \\ 3LPT, Master Teacher 1, \\ San Bartolome High School, \\ Department of Education, \\ Novaliches, Quezon City, Philippines \\ ${ }^{4}$ Assistant Professor, Dr., \\ Faculty of Education, \\ University of Benghazi, \\ Benghazi, Libya
}

\begin{abstract}
:
The integration of knowledge during the online classes influences the module tutors in the integration of technology in teaching with professional knowledge and belief which is focused on the learning enhancement of students. The study aims to identify issues in the online classes and to integrate knowledge in their learning enhancement. The research design employs both quantitative and qualitative research design because it is appropriate to investigate the integration knowledge of the online classes of students in their learning enhancement. It is suitable research choice in effective perform scientific research based on the characteristics and objectives available in support of the design in the study. Purposive sampling is utilised in the study because it is non-probable, which is subjective, selective, and judgmental. It is focused on the techniques utilise by the researchers. It assesses the impact of the study that deals on the attitude and behavior of students in the integration of knowledge during the online classes and learning enhancement. The subjects of the study are the selected private Higher Education Institution (HEI) students who are registered through online classes. The study comprised thirty (38) students. It is conducted for the spring 2019-2020.Results show that
\end{abstract}

iCorrespondence: email loviedsunbright_0722@yahoo.com.ph, eduardocarag@yahoo.com.ph, jomallillin@yahoo.com, regie0407@gmail.com 
most of the issues in the integration of knowledge through online classes in the learning enhancement of students are the internet connection and internet devices which are weak that can affect the learning process because of the many Wi-Fi users which lead to weak network connection, issues in online classes have to do with technology and program of virtual learning particularly on Wi-Fi connection that can affect the students learning process, and destruction of learning of the respondents struggle in the adoption of the traditional classroom to online learning setting which is difficult for them adjust. Audio or voice destruction hinders them in their learning process, integration of knowledge has to do with the lack of clarity of voice, choppy, and sometimes cannot be heard, and learning enhancement has to do with the time schedule of the online which clashes with household chores like cooking, cleaning, and washing.

Keywords: issues in online learning, destruction of learning, integration of knowledge, learning enhancement, online classes, issues in online classes

\section{Introduction}

Online classes are lessons conducted through the use of technology and are being conducted through internet. It is a system of management in learning on the modules provided by the students for their syllabus to be accomplished for the whole semester. It is a flexible program in the completion of their coursework module as part of their requirements. Focus and set time for the online lesson which is important and significant to the learners' success. It provides learning knowledge on the part of students when taken seriously because online study is different from traditional classroom learning. Learning enhancement of students will diminish when online class is taken for granted because the module tutor will just discuss and cannot monitor the students personally whether they listen or not. This has an effect on their performance to their academics, (Baker, Evans, Li, \& Cung, 2019). On the other hand, one of the techniques used in the online classes is the video or audio lectures. However, other students are hiding themselves, though it is affective because you can see or hear them during the lecture. It is an effective means of providing coursework among students in the infusion of learning in teaching. It focuses on the student-centered learning as if the learning is done inside the classroom.

The impact of video or audio learning during the online classes can boost the morale of students in their learning process balancing with the integration of course materials that provide information on their learning effectively on their course module (Scagnoli, Choo, \& Tian, 2019).

Hence, online lesson is very timely to students who are registered at present and cannot attend their classes because of the lockdown declared by the government in coordination with the different ministries of education. The Commission of Higher Education (CHED) or the Ministry of Higher Education (MOHE) takes the initiatives to have the online classes among students under their jurisdiction and is mandatory so that 
learning enhancement will not be affected. Nevertheless, online classes are flexible to comply with the course requirement of the module. Guidelines are set for students to follow and to include their online assessment. This can help students to experience and access learning through online (Owens, Suskin, \& Wiesemann, 2019).

Nevertheless, the integration of knowledge during the online classes influences the module tutors in the integration of technology in teaching with professional knowledge and belief which is focused on the learning enhancement. The impact of technology identifies and promotes expertise of module tutors. The influences and the values of the online classes and technology are significant on the pedagogy of learning, which is relevant to learning situation of students (Taimalu, and Luik, 2019). Hence, technology in online class is amazing for the teaching tool of the module tutors. It is appropriate in development of learning on the part of students. The application helps teachers to collaborate and create knowledge of wisdom among students who are the center of learning (Paciga, Fowler, \& Quest, 2019).

Moreover, the enhancement of learning in online classes are blended on techniques and approaches effectively in increase learning enrichment and resources in teaching which is incorporated in class discussion. Blended learning is very significant in teaching environment of online classes that lead to learning and self-pace experiences of students' outcome in their learning process appropriately in the effectiveness of teaching and the management of the course syllabus. It is a systematic approach and dynamic design of learning which is crucial in the integration of activities based on the needs of student lesson and implementation. Knowing the effectiveness of student abilities and capabilities in the blended activities for the improved design of learning and modules' perspective in the delivery of the course output which is critical on both tutors and learners which increase the awareness of the module tutors to transform blended courses develop on the engagement during the online classes effectively and approaches (Serrano, Dea-Ayuela, Gonzalez-Burgos, Serrano-Gil, \& Lalatsa, 2019). On the other hand, the focus on the learning enhancement is attention and development of competency of tutors to provide quality of learning. Module tutor is the key for the success of the learning output of students in an online class.

Development of the digital skills of tutors or teachers enhanced the learning technology used for their development of career and professionalism (Ulmane-Ozolina, Jansone, Magazeina, and Barute, 2019). In addition, the role of the higher education is to develop a curriculum in online class that is accessible to all the learners where they can instill education through the help of technology. It is a technology of persuasiveness, collaboration, interactive since learning process is a two-way process. It is an adoption of technology of learning in a context of education. The enhancement of learning must possess the characteristic of models which are needed on authenticity, personalise, lifelong, ubiquitous, and collaborative support on technology of learning. Open technology must be done during the online courses. It is a place of classroom learning that progresses the setting of online. It requires technology and facility to support 
learning of students. It supports and assists the module tutors to the most adopted technology relevant to learning (Isaias, 2018).

Similarly, the issues of online classes must be addressed to have a smooth learning process of students. Students' development in learning should be participated actively in the discussion of the tasks. Issues are the internet connection, audio, video, noisy environment, and choppy voices of the module tutor. Therefore, strategy and technique pedagogy must be developed to address the issue in online classes. The variations of the scientific strategies can sustain the competency of the learners' attitude and behavior toward their lesson. Identifying issues and evidences, implications, suggestions, and strengthens the background of techniques in teaching toward the goal of learning to students (Tsai, 2018). Besides, online classes and courses in the higher education is widely demand and relevant in the learning principles of teaching. It assesses the process of learning and teaching in terms of the quality set by the college or university which is the standard procedures in the profession. It identifies the issues in the implementation of the effective online learning classes through technology. The lack of skills needed in the online classes affect the learner and the inability to interact with students and module tutors. This becomes insufficient on the learning process and enhancement. Issues must be limited because learning is important to have a better output and improve the academic performance of students (Leontyeva, 2018). These have been proven by Park, Crocker, Nussey, Springate, \& Hutchings, (2019), they stressed that teaching evaluation of online graduate using the wiki tool provides information in the programs of online education. It engages student to foster technology in the process of learning which is necessary in the environment of online learning.

\section{Objectives}

1) To identify issues in the online classes and issues in the integration of knowledge in the learning enhancement.

2) To integrate knowledge in the online classes and in the learning enhancement of students.

\section{Research Questions}

1) What are the issues in the online classes and in the integration of knowledge in the learning process?

2) How integration of knowledge can be enhanced in the learning process of students in the online classes?

\section{Theoretical Lens}

The study is anchored on the theory cited by Panigrahi, Srivastava, \& Sharma, D. (2018) on "Online learning: Adoption, continuance, and learning outcome a review of 
literature" which focuses on the facilitation and the uses of technology in training and learning outcome worldwide. This is to stream down the issues in the traditional learning temporally. They introduce the online learning where it serves as benefits to students in the online learning challenges and platforms. Different review of literature has proven the adoption and factors affecting the usage of technology in the outcome learning of students. The integration of virtual and online learning fosters engagement of student in obtaining the outcome of learning to the fullest.

\section{Research Design}

The study employs both quantitative and qualitative research design because it is appropriate to investigate the integration knowledge of online classes of students in the learning enhancement. It is suitable research choice in effective perform scientific research based on the characteristics and objectives availability in support of the research design (Basias, \& Pollalis, 2018). On the other hand, it examines the standard and appropriate method of discipline. It describes the standard flow of the research guides developing the mixed method of research which is the qualitative and quantitative. It honors both the tradition, report, and method styles. This is appropriate inquiry to the different approaches of the study process (Levitt, et al., 2018).

\subsection{Sampling Techniques}

Purposive sampling is utilised in the study because it is non-probable, which is subjective, selective, and judgmental. This focuses on the techniques utilised by the researchers. It assesses the impact of the study that deals on the attitude and behavior of students in the integration of knowledge during the online classes and learning enhancement. It explicit the methods of purposive sampling adopting the knowledge and context in exploring the phenomena of the study based on the issues of online classes among the respondents. It illustrated the issues of online classes encountered by the respondents (Serra, Psarra, \& O'Brien, 2018).

\subsection{Respondents of the Study}

The subjects of the study are the selected private Higher Education Institution (HEI) students who are registered through online classes. These are students who have modular classes online. The study comprised thirty (38) respondents. It is conducted for the spring 2019-2020.

\subsection{Research Instruments}

Two sets of questions are given to the respondents which are the issues in online classes and the knowledge integration of learning enhancement of students. This is sent through email of the possible participants to have enough time to answer and to analyse the questions given to them. Participants are required to answer the questions based on their 
personal experiences and issues during the online classes. After which the answers from the participants are gathered for further analysis.

\subsection{Procedure in Gathering Information}

Information of this study is acquired through observation because there is a need to address the issues on the integration of knowledge through online classes in the learning enhancement of students.

\section{A. Mapping}

It was observed that online class from students show struggles, since it is their first time to have their modular classes online. They will be shocked from traditional classroom to online setting with the use of technology. It augments the concept on multidimensional system in learning (Chen, Huang, \& Chou, 2019).

\section{B. Formulation of Instruments}

After the mapping made, the researchers formulated a questionnaire for the integration knowledge through online classes of students. This is done through reading in the net, and other researches for the topic under investigated.

\section{Validation}

The instrument underwent a validation process to the expert researchers and underwent a critical analysis on the questions given to the respondents. All the suggestions are given emphasis. The instrument research reliability is essential in the analysis of the questionnaire suitable to the theory and concept of the study (Mohamad, Sulaiman, Sern, \& Salleh, 2015).

\section{Floating of the Questionnaire}

Since classes are online. Questionnaire is floated online. Students are required to answer based on their experiences during the online classes. They explained the different issues in online classes. This is sent through their email. Answers of the questionnaires are sent back to the researchers for further analysis.

\section{E. Gathering of Data}

Respondents are given enough time to answer the questionnaires so their studies will not be affected and are based on the research ethics.

\section{F. Analysis}

After the gathering of data, analysis is made for proper discussion on the integration of the knowledge through online classes in the learning enhancement of students.

\subsection{Trustworthiness of the Study}

In the research ethics credibility and trustworthiness is an important factor to consider. Proper procedure must be given emphasis. Criteria of the study are best evaluation of trustworthiness and credibility of the research through transferability, dependability, and confirmability. These criteria determine and demonstrate the research truthfulness. It explains the analysis, the credibility, the confidence, and the real or true findings of the study. It describes the neutrality degree that reflects to the opinion of the participants' 
experiences, motivation, and interest. Authenticity depicts the accuracy of the result of the study collected (Kyngäs, Kääriäinen, \& Elo, 2020).

\subsubsection{Transferability}

It generalises to apply and to attempt context in situation that definitely prove and cannot interpret data or transfer to establish the same and must be unique and have its own identity. It maximizes the context relative data collection on the question in the research and it serves as a pathway in the generalisation of the research. It conceptualises the knowledge of transfer sufficient and relevant aspect in the study problems (Adler, Hadorn, Breu, Wiesmann, \& Pohl, 2018).

\subsubsection{Dependability}

It is most use in the qualitative research which believes of the demonstrated credibility and dependability. It permits terms that is related to the study which validates reliability and content of the data. It assesses the validity of the data usage. It determines the circumstances and situation in the research. It is sufficient for the content information. It provides an assessment and dependability in the decision-making maintenance of the treatment and evaluation practice in research (Chemweno, Pintelon, Muchiri, \& Van Horenbeek, 2018).

\subsubsection{Confirmability}

The goal is not to replicate the work of others or research conducted. It is a natural process in the conduct of the study. It describes the properties, rules, and category of research in a qualitative design. Ultimately, it justifies the data inclusions as basis of replicability, confirmability and dependability in research implicit the assumptions, values, and concept of the decision in research and the application of the theory in the study (Korstjens, \& Moser, 2018).

\section{Results of the Study}

Table 1 shows the frequency and percentage distribution of the different issues in online classes among the respondents. As noted in the table, Internet connection and devices are weak and many Wi-Fi users that lead to weak network, with a frequency of 36 or 95\% among the respondents. Struggle in the adoption of traditional classroom to online learning is difficult, cannot hear the voice of the lecturer that hinders students to learn, and time schedule of online clashes with household chores like cooking, cleaning, and washing, with a frequency of 33 or $87 \%$ among the respondents. Lack of clarity of voice, choppy, and sometimes voice cannot be heard, explanation is not clear in some cases due to audio problems, and very noisy environment, different sounds are being heard, with a frequency 29 or $76 \%$ among the respondents. Some students cannot understand the lesson online, there is a problem in the features of Microsoft team (online program) like opening of videos, clips, and audios which are not functioning properly, and malfunction 
of audio and microphone where voices are not heard for both students and lecturer, with a frequency of 25 or $66 \%$ among the respondents. Communication and voices are choppy, with a frequency of 20 or $53 \%$ among the respondents. Communication programs in the college online are a big problem, and uncomfortable to study, with a frequency of 18 or $47 \%$ among the respondents. Some students cannot express well their opinion, with a frequency of 15 or $39 \%$ among the respondents. Members of the family destruct during online lesson, with a frequency of 11 or $29 \%$ among the respondents. Online study is for attendance purposes only, with a frequency of 9 or $24 \%$ among the respondents, and the least in rank is the inability to focus on the lesson, and unavailability of materials to study like books, and other materials of learning, with a frequency of 7 or $18 \%$ among the respondents.

Table 1: Online Classes Issues among Students

\begin{tabular}{|l|l|c|c|c|}
\hline & Indicators & $\mathrm{F}$ & $\%$ & $\mathrm{R}$ \\
\hline 1. & Lack of clarity of voice, choppy and sometimes cannot be heard. & 29 & 76 & 7 \\
\hline 2. & Cannot hear the voice of the lecturer that hinders students to learn. & 33 & 87 & 4 \\
\hline 3. & $\begin{array}{l}\text { Time schedule of online clashes with household chores like cooking, cleaning, and } \\
\text { washing. }\end{array}$ & 33 & 87 & 4 \\
\hline 4. & Explanation is not clear in some cases due to audio problems. & 29 & 76 & 7 \\
\hline 5. & Students cannot understand the lesson online. & 25 & 66 & 10 \\
\hline 6. & Inability to focus in the lesson & 7 & 18 & 18.5 \\
\hline 7. & Unavailability of materials to study like books and other materials of learning. & 7 & 18 & 18.5 \\
\hline 8. & Internet connection and devices are weak. & 36 & 95 & 1.5 \\
\hline 9. & Many Wi-Fi users that lead to weak network. & 36 & 95 & 1.5 \\
\hline 10. & $\begin{array}{l}\text { There is a problem in the features of Microsoft team (online program) like opening } \\
\text { of videos, clips, and audios. }\end{array}$ & 25 & 66 & 10 \\
\hline 11. & $\begin{array}{l}\text { Malfunction of audio and microphone where voices are not heard for both } \\
\text { students and lecturer. }\end{array}$ & 25 & 66 & 10 \\
\hline 12. & Communication and voices are choppy. & 20 & 53 & 12 \\
\hline 13. & Communication programs in college online are a big problem. & 18 & 47 & 13.5 \\
\hline 14. & Members of the family destruct during online lesson. & 11 & 29 & 16 \\
\hline 15. & Very noisy environment, different sounds are being heard. & 29 & 76 & 7 \\
\hline 16. & Uncomfortable to study. & 18 & 47 & 13.5 \\
\hline 17. & Students cannot express well their opinion. & 15 & 39 & 15 \\
\hline 18. & Online study is for attendance purposes only. & 9 & 24 & 17 \\
\hline 19. & Struggle in the adoption of traditional classroom to online learning is difficult. & 33 & 87 & 4 \\
\hline
\end{tabular}

The thematic analysis and identification of ideas were categorised based on the response of the respondents. Responses were classified into General when the similar responses were $50 \%$ or more, Typical when the similar responses were $25 \%$ up to $49 \%$, and Variant when similar responses fell below $25 \%$. Verbatim content or text is included in the elaboration of answers and presentation. 
Table 2: Themes and Ideas in the Integration Knowledge and Learning Enhancement in Online Classes

\begin{tabular}{|c|c|c|}
\hline Themes & Frequency of Response & Ideas \\
\hline $\begin{array}{l}\text { Issues in } \\
\text { online learning }\end{array}$ & $\begin{array}{l}\text { General } \\
\text { General } \\
\text { General } \\
\text { General } \\
\text { General }\end{array}$ & $\begin{array}{l}\text { - Malfunction of audio } \\
\text { - Weak internet connection and devices } \\
\text { - Too many Wi-Fi users } \\
\text { - Explanation is not clear } \\
\text { - Voices are choppy }\end{array}$ \\
\hline $\begin{array}{l}\text { Destruction of } \\
\text { learning }\end{array}$ & $\begin{array}{l}\text { General } \\
\text { Typical } \\
\text { General } \\
\text { General }\end{array}$ & $\begin{array}{l}\text { - Voice of the lecturer } \\
\text { - Members of the family } \\
\text { - Noisy environment } \\
\text { - Struggle in the adoption of the learning process }\end{array}$ \\
\hline $\begin{array}{l}\text { Integration of } \\
\text { knowledge }\end{array}$ & $\begin{array}{l}\text { General } \\
\text { Variant } \\
\text { General } \\
\text { Typical } \\
\text { Typical }\end{array}$ & $\begin{array}{l}\text { - Lack of clarity } \\
\text { - Inability to focus } \\
\text { - Microsoft team features } \\
\text { - Online programs } \\
\text { - Uncomfortable }\end{array}$ \\
\hline $\begin{array}{l}\text { Learning } \\
\text { enhancement }\end{array}$ & $\begin{array}{l}\text { General } \\
\text { General } \\
\text { Variant } \\
\text { Typical } \\
\text { Variant }\end{array}$ & $\begin{array}{l}\text { - Schedule time of classes } \\
\text { - Students cannot understand the lesson } \\
\text { - Unavailability of materials } \\
\text { - Students cannot express themselves } \\
\text { - Attendance }\end{array}$ \\
\hline
\end{tabular}

\section{Discussion}

\subsection{Issues in online classes}

Integration of knowledge through online classes in the learning enhancement varies in learning predicaments or learning styles of students. There are many issues in online classes. Based on the result of the study it shows that most problems are the internet connection and the devices used in online classes are weak because of poor connection of the $\mathrm{Wi}-\mathrm{Fi}$. Issues are the $\mathrm{Wi}-\mathrm{Fi}$ connection which is slow due to the bulk of the users. It provides communication inefficiency on the enhancement of students which is a vehicle framework to the learning process inputs and outputs on networks or Wi-Fi (Pokhrel, \& Choi, 2020).

On the other hand, struggling in the classroom adoption is too difficult among learners with surprise style of teaching, teachers, and improve the classroom model and setting (Stein, \& Graham, 2020) so with time frame and schedule of online classes that clashes with household chores like cooking, cleaning, and washing. Participants cannot hear the voice of the lecturer that hinders students to learn. In addition, the environment is very noisy because it is online, and they are being disturbed during the lesson. Explanation is not clear in some cases due to audio problems and lack of clarity of voice, choppy, and sometimes voice cannot be heard. Most of all the inability to focus on the lesson is a problem and unavailability of materials to study is missing. Ability to focus on the lesson will engage intellectual learning of students in a dynamic way to the learning enhancement (Barkley, \& Major, 2020). 


\subsection{Thematic analysis}

\section{A. Issues in online learning}

Issues in online learning classes of students cannot be escaped because of the many factors a teacher needs to consider. They said that issues in online classes are:

"Explanation is not clear in some cases due to audio problems." (P10 and P19, T1)

"Weak internet connection and devices." (P17, P13 and P10, T1)

"Many Wi-Fi users that leads to weak network." (P14 and P12, T1)

"Malfunction of audio and microphone where voices are not heard for both students and lecturer." (P15 and P10, T1)

\section{"Communication and voices are choppy." (P9, P7, and P4, T1)}

Furthermore, respondents say, they cannot understand the lesson because of audio problems encounter during the lecture. It is a building block in teaching and in the implementation of advance technology in the innovative learning and practices in the improvement of the educational system in teaching, Singh, \& Kumar, (2018). This is due to poor connection of the internet and the device use in online classes which is weak. In addition, there is a malfunction of the microphone and the audio for both students and lecturer. Similarly, the communication in the audio is choppy. This is a challenge in an online class for both lecturers and students in the usage of technology suitable for learning enhancement (Rasheed, Kamsin, \& Abdullah, 2020).

\section{B. Destruction of learning}

Destruction of learning can affect and hinder the integration of knowledge through online class in the learning enhancement of students. Destruction of the learning process of students involved the following and they say:

"Cannot hear the voice of the lecturer that hinders students to learn." (P11, and P21, T2)

"Members of the family destruct during online lesson." (P9, and P4, T2)

"Very noisy environment, different sounds are being heard." (P13, P10, and P6, T2)

"Struggle on the adoption of traditional classroom to online learning is difficult." (P20 P10, P3, T2)

Moreover, respondents encountered the problems in the communication process where the voice cannot be heard which challenged the learning enhancement of students. 
Aside from the disturbance they encounter during the online classes that members of the family disturbed them in which the focus of learning is affected. Noisy environment cannot be avoided due to the members of the family which are around during online classes (Tlili, Essalmi, Jemni, \& Chen, 2019). This brought them to struggle in the adoption of traditional learning in the classroom setting as compared to online setting done in the process of learning (Zan, 2020).

\section{Integration of Knowledge}

Integration of knowledge is significant to learning enhancement of students especially during online classes. This is important to consider on learning skills and ability to explore knowledge in the learning process. They say that:

"Lack of clarity of voice, choppy and sometimes voice cannot be heard." (P20, P5, and P4, T3)

"Inability to focus in the lesson." (P7, T3)

"There is a problem in the features of Microsoft team (online program) like opening of videos, clips, and audios." (P18, and P17, T3)

"Communication programs in the college online are a big problem." (P12, and P6, T3)

"Uncomfortable to study." (P12, P4, and P2, T3)

Nevertheless, knowledge integration is a factor where learning process is given emphasis. Respondents encounter lack of clarity of voice of the lecturer which cannot be heard. This affects the integration of learning and knowledge of students. The inability to focus on the lesson will also have an impact to them because the features of the program utilise in the online classes are not functioning properly like the audio, video clips and the slides. They encounter uncomfortable to study because program online is a big problem to them. The understanding of technology knowledge integration in online classes emphasise the competency and understanding of lecturers in support to discipline coherent in adoption program and framework in technology of online classes and learning enhancement (Nelson, Voithofer, \& Cheng, 2019).

\section{Learning Enhancement}

Learning enhancement is vital to the development of learning process of students. This is important in online classes; however, they say that:

"Time schedule of online clashes with household chores like cooking, cleaning, and washing." (P25, P6, and P2, T4) 
"Some students cannot understand lesson online." (P15, and P10, T4)

"Unavailability of materials to study like books and other materials of learning." (P7, T4)

"Some students cannot express well their opinion." (P10, and P5, T4)

"Online study is for attendance purposes only." (P4, P3, and P2, T4)

Nonetheless, schedule of online classes has clashes to the household chores. This has an impact to learning enhancement because it affects efficiency, positivity, convenience learning improvement, and enhancement among students (Stein, \& Graham, 2020). Similarly, learning enhancement is based on how the module tutors motivate students because most of them cannot understand lesson online due to unavailability of material during classes. They just only rely on the discussion during online lesson which is not enough from the learning enhancement. Some of them cannot express opinion online and they will just attend online classes for attendance purposes. Enhancing learning demonstrates the process of teaching in the learning online communities as based on theory of teaching which is significant to students learning skills (Olofsson, \& Lindberg, 2020).

\section{Conclusion}

In the light of the findings and result of the study, the conclusions are drawn.

1) It shows that most of the issues in the integration of knowledge through online classes in the learning enhancement are the internet connection and internet devices which are weak that can affect the learning process because of many WiFi users which lead to weak network connection.

2) It shows that issues in online classes have to do with the technology and programs of virtual learning particularly on Wi-Fi connections that can affect students learning process.

3) It shows that destruction of learning of the respondents struggle in the adoption of traditional classroom setting to online learning setting which is difficult for them to adjust. Audio or voice destruction hinders them in the learning process.

4) It shows that integration of knowledge has to do with lack of clarity of voice, choppy, and sometimes voice cannot be heard.

5) It shows that learning enhancement has to do with time schedule of online which clashes with household chores like cooking, cleaning, and washing.

\subsection{Recommendation}

In the light of the conclusion in the study, the recommendations are drawn. 
1) Issues in the online classes must be addressed. Consider the trends of technology. Wi-Fi or internet must be given consideration. This has an impact to the knowledge integration and learning enhancement of students.

2) There must be good source of internet connection or Wi-Fi that can improve in the issues of online classes among the respondents. Wi-Fi providers should consider this as a part of the services in the community.

3) Since there is a struggle of the adoption of classroom setting compared to virtual learning or online learning setting. Proper motivation of learning must be given emphasis among students to include the benefits of learning in online classes and for learning enhancement.

4) Integration of knowledge is important among students; therefore, well-modulated voice must be needed, voice must be clear enough so that learners can hear and follow the learning procedures in online classes.

5) Set aside household chores during learning enhancement of students. This can disturb students during the learning process. There must be isolation of place during online classes which is free from any disturbances during the learning period.

\section{References}

Adler, C., Hadorn, G. H., Breu, T., Wiesmann, U., \& Pohl, C. (2018). Conceptualizing the transfer of knowledge across cases in transdisciplinary research. Sustainability science, 13(1), 179-190.

Baker, R., Evans, B., Li, Q., \& Cung, B. (2019). Does inducing students to schedule lecture watching in online classes improve their academic performance? An experimental analysis of a time management intervention. Research in Higher Education, 60(4), 521-552.

Barkley, E. F., \& Major, C. H. (2020). Student engagement techniques: A handbook for college faculty. John Wiley \& Sons.

Basias, N., \& Pollalis, Y. (2018). Quantitative and qualitative research in business \& technology: Justifying a suitable research methodology. Review of Integrative Business and Economics Research, 7, 91-105.

Chemweno, P., Pintelon, L., Muchiri, P. N., \& Van Horenbeek, A. (2018). Risk assessment methodologies in maintenance decision making: A review of dependability modelling approaches. Reliability Engineering \& System Safety, 173, 64-77.

Chen, C. H., Huang, C. Y., \& Chou, Y. Y. (2019). Effects of augmented reality-based multidimensional concept maps on students' learning achievement, motivation and acceptance. Universal Access in the Information Society, 18(2), 257-268.

Isaias, P. (2018). Model for the enhancement of learning in higher education through the deployment of emerging technologies. Journal of Information, Communication and Ethics in Society. 
Korstjens, I., \& Moser, A. (2018). Series: practical guidance to qualitative research. Part 4: trustworthiness and publishing. European Journal of General Practice, 24(1), 120-124.

Kyngäs, H., Kääriäinen, M., \& Elo, S. (2020). The Trustworthiness of Content Analysis. In the Application of Content Analysis in Nursing Science Research (pp. 41-48). Springer, Cham.

Leontyeva, I. A. (2018). Modern distance learning technologies in higher education: Introduction problems. Eurasia journal of mathematics, science and technology education, 14(10), em1578.

Levitt, H. M., Bamberg, M., Creswell, J. W., Frost, D. M., Josselson, R., \& Suárez-Orozco, C. (2018). Journal article reporting standards for qualitative primary, qualitative meta-analytic, and mixed methods research in psychology: The APA Publications and Communications Board task force report. American Psychologist, 73(1), 26.

Mohamad, M. M., Sulaiman, N. L., Sern, L. C., \& Salleh, K. M. (2015). Measuring the validity and reliability of research instruments. Procedia-Social and Behavioral Sciences, 204, 164-171.

Nelson, M. J., Voithofer, R., \& Cheng, S. L. (2019). Mediating factors that influence the technology integration practices of teacher educators. Computers $\mathcal{E}$ Education, 128, 330-344.

Olofsson, A. D., \& Lindberg, J. O. (2020). Informed design of educational technologies in higher education: Enhanced learning and teaching. Simulation, 379.

Owens, K., Suskin, M., \& Wiesemann, C. (2019, October). Bringing Campus Experience to Online Classes. In Proceedings of the 2019 ACM SIGUCCS Annual Conference (pp. 61-63).

Paciga, K. A., Fowler, A., \& Quest, M. (2019). Constructing Preservice Teachers' Knowledge of Technology Integration. In Advanced Methodologies and Technologies in Modern Education Delivery (pp. 879-892). IGI Global.

Panigrahi, R., Srivastava, P. R., \& Sharma, D. (2018). Online learning: Adoption, continuance, and learning outcome-A review of literature. International Journal of Information Management, 43, 1-14.

Park, C. L., Crocker, C., Nussey, J., Springate, J., \& Hutchings, D. (2019). Evaluation of a teaching tool-wiki-in online graduate education. Journal of Information Systems Education, 21(3), 5.

Pokhrel, S. R., \& Choi, J. (2020). Improving TCP Performance over Wi-Fi for Internet of Vehicles: A Federated Learning Approach. IEEE Transactions on Vehicular Technology.

Rasheed, R. A., Kamsin, A., \& Abdullah, N. A. (2020). Challenges in the online component of blended learning: A systematic review. Computers $\mathcal{E}$ Education, 144, 103701.

Scagnoli, N. I., Choo, J., \& Tian, J. (2019). Students' insights on the use of video lectures in online classes. British Journal of Educational Technology, 50(1), 399-414.

Serra, M., Psarra, S., \& O'Brien, J. (2018). Social and physical characterization of urban contexts: Techniques and methods for quantification, classification and purposive sampling. Urban Planning, 3(1), 58-74. 
Serrano, D. R., Dea-Ayuela, M. A., Gonzalez-Burgos, E., Serrano-Gil, A., \& Lalatsa, A. (2019). Technology-enhanced learning in higher education: How to enhance student engagement through blended learning. European Journal of Education, 54(2), 273-286.

Singh, D., \& Kumar, M. (2018). Integration of Audio-Visual and Traditional Practices for Effective Classroom Teaching. Advanced Journal of Social Science, 3(1), 47-49.

Stein, J., \& Graham, C. R. (2020). Essentials for blended learning: A standards-based guide. Routledge.

Taimalu, M. and Luik, P., (20190. The impact of beliefs and knowledge on the integration of technology among teacher educators: A path analysis. Teaching and Teacher Education, 79, pp.101-110.

Tlili, A., Essalmi, F., Jemni, M., \& Chen, N. S. (2019). A Complete Validated Learning Analytics Framework: Designing Issues from Data Use Perspective. International Journal of Information and Communication Technology Education (IJICTE), 15(3), $42-59$.

Tsai, C. Y. (2018). The effect of online argumentation of socio-scientific issues on students' scientific competencies and sustainability attitudes. Computers E Education, 116, 14-27.

Ulmane-Ozolina, L., Jansone, A., Magazeina, I. and Barute, D., 2019. Technology enhanced learning in teachers' professional development. Periodicals of Engineering and Natural Sciences, 7(1), pp.216-221.

Zan, C. Skills, practice and challenges in the adoption of learning technologies in training and adult education. Research Repository, 76. 
Authors will retain the copyright of their published articles agreeing that a Creative Commons Attribution 4.0 International License (CC BY 4.0) terms will be applied to their work. Under the terms of this license, no permission is required from the author(s) or publisher for members of the community to copy, distribute, transmit or adapt the article content, providing a proper, prominent and unambiguous attribution to the authors in a manner that makes clear that the materials are being reused under permission of a Creative Commons License. Views, opinions and conclusions expressed in this research article are views, opinions and conclusions of the author(s). Open Access Publishing Group and European Journal of Open Education andE-learning Studies shall not be responsible or answerable for any loss, damage or liability caused in relation to/arising out of conflict of interests, copyright violations and inappropriate or inaccurate use of any kind content related or integrated on the research work. All the published works are meeting the Open Access Publishing requirements and can be freely accessed, shared, modified, distributed and used in educational, commercial and non-commercial purposes under a Creative Commons Attribution 4.0 International License (CC BY 4.0). 